\title{
A POLÍTICA EXTERNA BRASILEIRA E A FORMAÇÃO DO TERRITÓRIO: DA DISCUSSÃO CONCEITUAL À ANÁLISE DA POLÍTICA EXTERNA DA DÉCADA DE 1930 E O ACORDO COMERCIAL DE 1935
}

\author{
Caio Cursini ${ }^{1}$
}

Resumo: Ao longo desse artigo é apresentado o debate sobre geografia, política externa, relações internacionais e território, de modo a procurar compreender a relação entre a formação territorial do Estado brasileiro na tecitura da política externa do país. Para isso, extraímos a compreensão sobre a geografia contida nas obras de alguns internacionalistas clássicos, para em seguida aproximarmos o debate geográfico do campo da política externa, buscando questionar a concepção das relações internacionais que têm considerado o território não somente como homogêneo, mas também como estático. A análise do acordo comercial de 1935 entre - Brasil e os Estados Unidos é o marco factual que utilizamos para nos acercar da política externa na década de 1930 , analisada aqui a partir da documentação diplomática, o que nos sugerirá não somente a construção dialética entre o território nacional e a política externa, mas também a indispensabilidade da geografia como uma área do conhecimento necessária para a compreensão da política externa brasileira.

Palavras-Chave: Geografia; relações internacionais; diplomacia; território

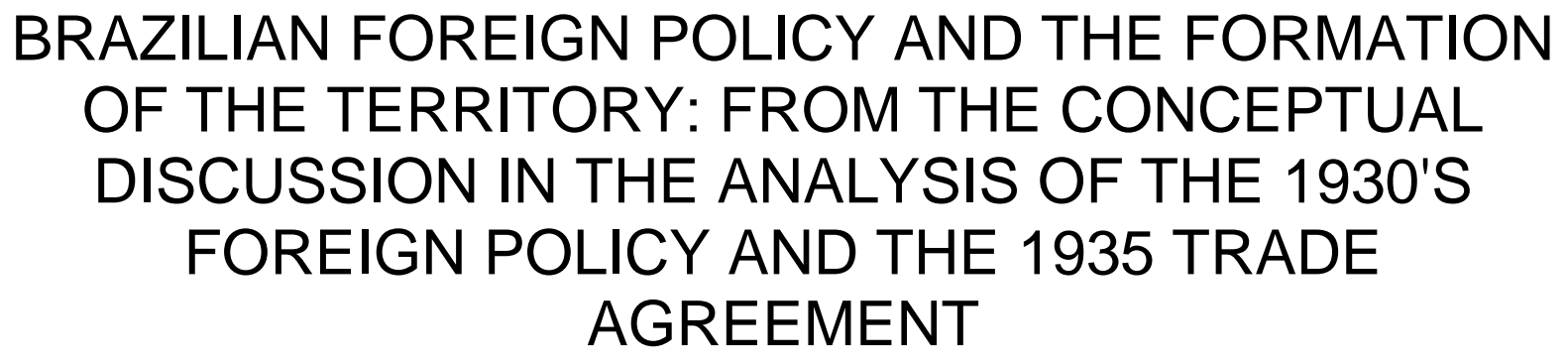

Abstract: This article has presented the debate about geography, foreign policy, international relations, and territory so that we seek to understand the relationship between the territorial formation of the Brazilian State in the fabric of the country's foreign policy. For this, we extract the understanding of geography contained in the works of some classical internationalists and then bring the geographical debate closer to the field of foreign policy, seeking to question the conception of international relations that have considered the territory not only as homogeneous but also as static. An analysis of the 1935 trade agreement between Brazil and the United States is the factual framework we used to approach foreign policy in the 1930s, analyzed in Diplomatic Documents, which will not only suggest the dialectical construction between the national territory and foreign policy, but also the indispensability of geography as a necessary area of knowledge for understanding Brazilian foreign policy.

Key-Words: geography; international relations; diplomacy; territory

\footnotetext{
${ }^{1}$ Doutorando em Geografia com ênfase em Geopolítica na Universidade de São Paulo (USP).
} 


\section{INTRODUÇÃO}

É no mínimo curioso o fato de que a política externa brasileira é raramente analisada pela geografia. A geopolítica, talvez o campo de estudo mais próximo às dinâmicas das relações internacionais e seus debates, ainda que tangencie diversos fatores da política internacional, não se atêm diretamente à análise do território brasileiro como categoria fundamental para a formulação das políticas de Estado. Geopolíticos como, Golbery do Couto e Silva, Carlos Meira Mattos, Mário Travassos, entre outros, provenientes do campo militar sopesaram o território enquanto um fator determinante para a "posição de poder" no cenário mundial. No entanto, a análise geopolítica, ao menos do ponto de vista da geopolítica clássica, concentra-se no exame do poder como um elemento intrínseco e indispensável ao Estado-Nação. Desse modo, essa perspectiva parte da noção de um território estático, muito distante da concepção de formação contínua do território, bastante debatida por, Andrade (2004), Moraes (2005), Castro (2005), Saquet (2007), Saquet e Silva (2011), Agnew (2003; 2018) entre outros estudiosos e estudiosas do campo geográfico. A proposta desse artigo é aproximar a discussão em relação à política externa, tomando como objeto de estudo alguns eventos da diplomacia brasileira durante a década de 1930.

Com esse intuito, analisamos uma série de documentos retirados do Centro de Pesquisa e Documentação de História Contemporânea do Brasil (CPDOC) ${ }^{2}$. Esses registros, são cartas, anotações e dados apresentados entre os atores da política externa brasileira durante o período mencionado, principalmente em 1935, data do acordo comercial entre o Brasil e os Estados Unidos. Essa construção histórica se faz importante para compreendermos a dinâmica dos grupos de poder no Brasil, assim como ajuda a esclarecer a estrutura do território brasileiro daquele período. O que propomos com essa análise é que a reestruturação do território brasileiro em função da política externa da década de 1930, culminando com o acordo comercial de 1935, ratificou a posição brasileira enquanto um Estado fornecedor de matérias primas aos países centrais.

São analisados, também, os dados referentes à produção agrícola e industrial do país, informações retiradas do Instituto Brasileiro de Geografia e Estatistica (IBGE), de modo a fornecer-nos o panorama econômico e social, na tentativa de esclarecer o território, não como um objeto estático, como o interpretam alguns dos principais teóricos internacionalistas, como Clausewitz (1992), Aron (2002) e Morgenthau (2003), mas uma categoria de análise em constante formação.

Dividimos esse artigo em duas partes. Na primeira, buscamos estabelecer alguns liames entre o território e a política externa, procurando, posteriormente, introduzir a negociação de 1935 dentro de um contexto da formação histórica do território brasileiro. Na segunda, principiámos com a análise da política externa da década de 1930, contextualizando-a, a partir dos seus documentos diplomáticos e, em seguida enfatizamos o acordo comercial de 1935.

\section{TERRITÓRIO E POLÍTICA EXTERNA, UMA BREVE DISCUSSÃO}

Como acordos comerciais e tratativas na política externa impactam diretamente na construção do território brasileiro? Essa questão chave para a aproximação entre a política externa e a geografia é também um desafio para o reestabelecimento de um

\footnotetext{
${ }^{2}$ Os documentos apresentados no teor do texto encontram-se referenciados em nota de rodapé da seguinte forma: nome do documento, data, número (quando houver) e nomenclatura do arquivo. Todos os documentos se encontram disponíveis no sítio < http://www.fgv.br/cpdoc/acervo/arquivo-pessoal>
} 
liame entre esses dois campos. Apesar de encontrarmos pontualmente alguma contribuição de teóricos como, Costa (2008), Becker (2012a; 2012b), Roseira (2015), Martin (1992; 2018) e Agnew (2003; 2018), a geografia acadêmica perdeu boa parte do seu contato com as discussões da política exterior, de modo que a sua produção científica e discussões sobre o território nacional foram apartados da reflexão tão cara à geografia - a formação histórica do território.

Quando mencionamos o conceito de "território" nos referimos a uma categoria de análise composta por conteúdo de ordem social, política, econômica e cultural, todos esses intrincados diante de um tempo histórico. O que se aproximaria da percepção duo dimensional em que, "o território usado seria um híbrido de duas dimensões: uma métrica ou geométrica e outra social" (Cataia, 2011, p.9).

Esse território se diferencia da percepção quase inerte muito presente nos clássicos das relações internacionais, como em Clausewitz (1992), Wight (2002), Aron (2002) e outros teóricos internacionalistas. Essa noção se resume bem na frase de que Morgenthau (2003, p.308) em que

qualquer que seja o nível tecnológico, é necessário um certo volume de população para assegurar a exploração de um território e tirar vantagem da divisão do trabalho, do suplemento de produtividade originado na força produtiva que nasce da cooperação.

Um território a ser explorado. Este compraz à lógica do poder do Estado, tonando-se fundamental para a lógica competitiva (quando não autofágica) do ambiente internacional. O território nacional, assumindo uma forma contígua daquela ratzeliana em que

a geografia política pode considerar um país habitado há muito tempo um espaço vazio, se o considerar ocupando uma posição (geográfica) a qual é irrelevante. Clausewitz certa vez chamou a Suíça de "lago" no sentido geográfico da guerra, uma vez que em um momento crítico, ela se comportou tão passivamente quanto um corpo d'água. (Ratzel, tradução nossa, 1896, p.78) ${ }^{3}$.

Esse esvaziamento do território, apesar de amplamente debatido na geografia enquanto uma grave problemática analítica, parece não fazer parte de muitas das reflexões internacionalistas da política externa. E isso tem causado óbices para o estudo do territóro brasileiro, isto porque: a)com efeito, tem-se perdido de vista, o território como categoria fundamental na consolidação da política externa; b)o impacto socio-economico das tratativas internacionais foi alienado da realidade territorial, já que o território perdeu seu conteúdo social; c)o Estado tem sido tomado como um agente incontestável da realidade internacional e o território, enquanto seu alicerce passou a ser passível de qualquer intervenção;

Esvaziar o território de seu conteúdo socio-econômico serve a uma função importante para a acumulação de capital. Como Santos (1994, 2003, 2006) explica, os objetos que formam o espaço possuem funções. A política externa chancela esse fluxo de intencionalidade e condiciona esses objetos. Em outras palavras, a

\footnotetext{
${ }^{3}$ Die politische Geographie kann ein längst bewohntes Land, selbst ein geschichtliches sich als einen leeren Raum vorstellen, wenn sie es in einer Stellung betrachtet, für die es gleichgiltig, ob es bewohnt ist oder nicht. So nennt Clacsbwitz einmal die neutrale Schweiz im kriegsgeographischen Sinn einen See. Sie verhielt sich eben in einem kritischen Augenblick gerade so passiv wie eine Wasserfläche.
} 
territorialização da divisão internacional do trabalho não é materializada naturalmente por um Estado, mas moldada por acordos da política internacional. O território é construído de acordo com uma lógica produtiva, no entanto, esta não é assimilada sem ser apressiada pelo Estado e seus atores.

O fato de que a expansão do capital, como indica Harvey (2011) necessita se expandir geograficamente para a continuidade do processo de acumulação faz da política externa uma entidade fundamental para esse processo. Desse modo, afirma Moraes (2005, p.84) que "quanto maior a fraqueza do Estado, maior a possibilidade tanto da sua manipulação por interesses estrangeiros, como sua utilziação interna por interesses privados". Fato este que explicita que o imperialismo deixa seus testemunhos, antes de tudo, nos atores da política externa e, por conseguinte, nos documentos desta.

Nesse âmbito encontramos as análises de Agnew (2003, p.29) que apontam a relação do poder do Estado no campo internacional, a partir da "definição territorial do espaço", indicando, inclusive que a ordem do cenário internacional tem necessariamente características geográficas. Discutindo o pensamento do geógrafo Jean Gottmann, Agnew (2018) observa que o território do Estado é estruturado para compor a esfera das relações internacionais e, a partir disso é incorporada a perspectiva de território à noção "divina" do Estado. Agnew (2018) também visualiza que a ideia de soberania nacional está fundada na concepção maquiavélica do poder do rei sobre o território e, no sentido que aponta Gottman (tradução nossa,1973, p.49) "o território torna-se a incorporação física e legal da identidade nacional". ${ }^{4}$

Por outro lado, Roseira (2015, p.75) indica que "sob a perspectiva das relações internacionais, o realismo político encontra poderoso eco no sistema teórico fundado por Ratzel", o que torna o território um elemento fundamental para o exercício do domínio e poder do Estado. É possível, portanto, que a partir disso, como observa Morgenthau (2003), o território passe a ser assimilado como um dos componentes da noção de "potencialidade" da entidade estatal, ao menos do ponto de vista internacionalista. A ótica de Morgenthau se complementa com o pensamento de Aron (2002, p.254) de que

o espaço pode ser considerado como meio, teatro e objetivo (motivo) da política externa. O terceiro desses conceitos é imediatamente inteligível. Como um Estado é considerado "proprietário" de um certo espaço, cada fragmento desse espaço pode ser objeto de conflito entre indivíduos e grupos.

Essa perspectiva das relações internacionais aproxima-se da observação de Roseira (2015, p.75) em que a "visão monolítica do Estado-Nação em grande parte obscurecendo suas heterogeneidades e conflitos internos, aspecto comum em geopolítica, é uma característica das teorias realistas e neorrealistas." Nesse sentido, Roseira (2015, p.85) assinala a relevância de "aprofundar o estudo da geopolítica, de modo a resgatar suas contribuições teóricas capazaes de estabelece-la, de fato, como uma disciplina e não como mero discurso ideológico sobre o Estado e o território".

É possível que a alienação do território responda à lógica internacional de subordinação de Estados periféricos ao julgo de potências internacionais. Apresentar o território nacional a partir de formulas quantitativas, ou seja, números sobre o desenvolvimento, crescimento econômico, urbanização, condições sociais, etc, denota-se, como diria Santos (2002), uma forma de se deixar de analisar os processos e enfatizar os resultados e isso possuí sua funcionalidade. Para Santos (2002), a

\footnotetext{
4 "The territory became the physical and legal embodiment of national identity"
} 
quantificação negligencia a humanidade e abre caminho para a acumulação do capital e a imposição de uma ordem verticalizada, do ponto de vista internacional, a subordinação dos Estados periféricos às grandes potências.

Essa percepção não é de modo algum ultrapassada. A política externa e interna brasileira está repleta de análises quantitativas do território nacional, reduzindo-o a um determinismo histórico que traça uma realidade vaga do ponto de vista cultural, político e socioeconômico, por exemplo. Em 1939, sobre a exploração de borracha no Brasil, Oswaldo Aranha escrevia a Vargas que,

a exploração de produtos tropicais é cara e exige o internamento (colonização), no hinterland, onde a natureza é opressiva [...] como poderia um brasileiro, pobre sem crédito, sem técnicos, atacar em larga escala o plantio da borracha em plena mata amazônica?" $(\text { Aranha, 1939) })^{5}$

Em 1977 no discurso de Ernesto Geisel na assinatura do Tratado de Cooperação Amazônica diria,

os países desta região não podem voltar as costas para o desafio amazônico e condenar a América do Sul a ser para sempre uma periferia sem centro, [...] sem linhas de comunicação que vivifiquem o coração vazio do continente (Silveira, 1977) ${ }^{6}$.

Em 1999 afirmaria Rubens Antônio Barbosa, embaixador brasileiro em Washington, sobre a Área de Livre Comércio nas Américas "o Brasil possui inúmeras vantagens locacionais [...] a localização geográfica do Brasil no continente, que opera como um redutor dos custos de transporte" (Barbosa, 1999).

A perspectiva de Souza (2009, p.62) auxilia-nos sobre essa ótica, segundo o autor "o 'território' por excelência, para o senso comum, mas também para juristas, militares e cientistas políticos - e até para geógrafos - terminou sendo, durante muito tempo, aquele "sobre o qual" o aparelho de Estado exerce a sua soberania". Esta perspectiva parece não estar restrita ao passado, mas vigente no aparelho de toda a política externa brasileira. Essa visão também parece não destoar do pensamento Maquiavélico de que o, "território é uma área controlada e fortificada que deve ser defendida e mantida sob domínio" (Maquiavel apud Saquet, 2007, p.28).

Esse território atrelado a um discurso geopolítico da criação do progresso, como o apresenta Silva (1981) é incorporado pela diplomacia brasileira há décadas. $\mathrm{Na}$ medida em que, "as ideologias geográficas têm sido reduzidas ao discurso específico da geopolítica" (Raffestin, 2009, p.26), que no Brasil, é bastante próximo da concepção golberiana ${ }^{8}$, o território tem se tornado uma categoria não só hegemônica, como muitas vezes homogênea. A partir disso, seguindo a visão de Roseira (2015) toda a multiplicidade substancial do território é reduzida à visão do Estado-nação.

\footnotetext{
${ }^{5}$ Carta de Oswaldo Aranha a Getúlio Vargas, s/d, documento nº11. GV c 1939.01.09.

${ }^{6}$ Projeto de discurso a ser pronunciado pelo senhor presidente da república, por ocasião da assinatura do Tratado de Cooperação Amazônica em 3 de julho de 1978. AAS mre ai 1977.03.02.

${ }^{7}$ Rubens Antônio Brabosa, embaixador do Brasil em Washington, publicado em Wagner Menezes (org.) direito internacional no cenário contemporâneo (Curitiba: Jurua, 2003), p.193-198. Alca e Mercosul: implicações estratégicas para o Brasil, 11 de julho de 1999.RBA mpc w 1999.03.10.

${ }^{4}$ Martin (2018) realiza uma interessante crítica sobre a visão de Golbery do Couto e Silva sobre o território brasileiro.
} 
Tomando a política externa de Getúlio Vargas na década de 1930, notaremos que esse panorama é dominante ao interior do Ministério das Relações Exteriores. Por exemplo, citava-se com frequência a necessidade de se consolidar a propaganda brasileira no exterior, principalmente nos Estados Unidos. Seguindo esse intuito, Oswaldo Aranha, embaixador brasileiro nos Estados Unidos em 1935, dizia a Vargas,

dá Getúlio, um cunho sério e ativo à propaganda do Brasil no exterior, porque estamos atravessando um período de abandono, de desleixo, enquanto os demais povos, mais do que nunca, estão cogitando de se defender e de se fazer conhecidos. Mandem-me livros, mapas, publicações, fotografias, enfim, tudo quanto possa dar uma ideia boa do Brasil e destruir as más, seja de que ministério for. (Aranha, 1935) ${ }^{9}$.

Comercializar o território brasileiro como um conjunto estável de estruturas era o mote da política externa do país na década de 1930, isso porque, a consolidação de Getúlio Vargas no poder era indispensável à perspectiva comercial do país. Como diria Harvey (2011) a exportação do capital exige uma base geográfica mais ou menos estável e na década de 1930, a classe capitalista estadunidense, temerosa após 1929 e aflita com as tensões na Europa, não deixava de se interessar pela possibilidade de multiplicar seus dividendos na América Latina ${ }^{10}$.

Em oposição à perspectiva internacionalista, o acordo de 1935 (assim como tantos outros) não é somente uma tratativa entre atores acerca de assuntos estritamente econômicos. Algumas inclinações industrialistas e urbanas do início de 1930, como destaca Fausto (2007b) não seriam suficientes para impedir que o governo Vargas aceitasse um acordo que incentivava a importação de manufaturas dos Estados Unidos, embora a pressão por parte dos industriais brasileiros tenha criado óbices à assinatura do acordo. Esse conflito não era somente retórico, a estrutura territorial brasileira modificava-se, com ela a sociedade. Ao se transformar o território, alterava-se os grupos de poder do Estado e, por consequência, as diretrizes da política externa brasileira, influindo, ora mais, ora menos, nas suas decisões.

No entanto, a embrionária reconfiguração territorial brasileira não impediria a assimilação da estrutura do poder internacional. Ao se confirmar à negociação entre os Estados Unidos e o Brasil se confirmaria a posição agroexportadora desse último país, assim como se assinalaria para as elites agrárias certa preponderância no campo político e econômico. O acordo comercial, serve-nos como um exemplo da imposição da ordem global na estruturação do território nacional, alterando as dinâmicas ao nível local, regional e federal.

\section{A POLÍTICA EXTERNA DE 1930 E O ACORDO COMERCIAL DE 1935: UMA INTERPRETAÇÃO GEOGRÁFICA A PARTIR DOS DOCUMENTOS DIPLOMÁTICOS}

É frequente que o território como "resultado das ações dos homens em sociedade, demarcando e organizando o espaço tanto jurídica como cultural e economicamente" (Gottmann apud Saquet, 2007, p.69), seja tomado como uma simples categoria para a intervenção do Estado. Como pudemos notar, a noção de geografia na política externa brasileira não é muito clara. Uma vez que a política

\footnotetext{
${ }^{9}$ Carta de Oswaldo Aranha a Vargas. Washington, 9 de abril de 1935. GV c 1935.04.09/1

${ }^{10} \mathrm{Em}$ carta de Oswaldo Aranha ao secretário de Estado norte-americano, Cordell Hull, cita-se por diversas vezes a cooperação brasileira com os Estados Unidos no intuito de não onerar o capital estadunidense em território brasileiro.

Carta de Oswaldo Aranha ao Secretário de Estado, 8 de março de 1939. GV c 1939.01.09.
} 
externa de um país está embebida de olhares dos principais teóricos internacionalistas, como os já mencionados, a geografia tende a se fragmentar em elementos mais ou menos estáticos, como recursos naturais, território, população, etc. Encontrar um olhar geográfico no interior da política externa brasileira não é uma tarefa simples, dado que a geografia no conteúdo dos documentos diplomáticos brasileiros ora é mais explícita, ora dissipa-se ao longo dos mais variados assuntos.

O acordo comercial de 1935 seria ratificado entre o Brasil e os Estados Unidos em 2 de fevereiro de 1935. No decreto no542 de dezembro desse mesmo ano, se expunha o teor do tratado, que reduziria ou manteria zerada as tarifas sobre uma série de produtos entre ambos os países. Da parte dos Estados Unidos seriam reduzidas as tarifas sobre mate, castanhas, mamonas, manganês, copaíba, além de se manter zerada as tarifas sobre vários produtos agrícolas, dentre eles, o café, o cacau e madeiras. Da parte brasileira as tarifas seriam reduzidas sobre uma série de produtos manufaturados e maquinários, como automóveis, motocicletas, máquinas agrícolas, equipamentos cirúrgicos, filmes, equipamento industrial, entre outros (Brasil, 1935).

É bem conhecido na historiografia que o posicionamento do governo Vargas até meados de 1940 era fruto de um intenso embate da diplomacia brasileira em barganhar meios para a industrialização do país, mais especificamente para o setor siderúrgico. A chamada autonomia na dependência, segundo Moura (1980) foi uma orientação da política externa brasileira durante o primeiro governo Vargas, dentro de uma esfera internacional em que o Brasil estava significativamente atrelado aos Estados Unidos. Nesse cenário foi possível certa margem de autonomia no âmbito das tratativas internacionais, resultando, por consequência, no êxito brasileiro, não somente em angariar recursos para a instalação de uma siderúrgica em Volta Redonda, mas também para o reaparelhamento das forças armadas no país ${ }^{11}$.

O longo embate do governo Vargas em lograr recursos para a instalação da usina siderúrgica de Volta Redonda estava inserido num âmbito mais amplo do ponto de vista internacional. No campo exterior, como destaca Moura (2012), a área de interesse dos Estados Unidos se expandia até o Nordeste brasileiro, em contraste à expansão das forças do Eixo no Norte da África. Além disso, os movimentos que antecediam a Segunda Guerra Mundial já indicavam a intenção estadunidense em aumentar sua área de influência por todo o continente americano, como demonstram Danese (2017), Moura (2012) e os próprios registros de Vargas, que deixam gravadas as impressões de Oswaldo Aranha sobre a good neighbor policy ${ }^{12}$ dos Estados Unidos:

Precisamos forçar a adaptação dessa política à única fórmula continental conveniente ao Brasil: o apoio à preeminência continental dos Estados Unidos, em troca do seu reconhecimento da nossa supremacia na América do Sul. (Aranha, 1937) ${ }^{13}$

Dentro deste contexto, em 1938, na VIII Conferência de Lima, era celebrada uma série de acordos entre os Estados americanos, afirmando a solidariedade continental em caso de intervenção estrangeira, o que obviamente colocava os Estados Unidos como depositário da segurança de todo o continente.

\footnotetext{
${ }^{11}$ Fausto (2007a) demonstrará que a relação entre o rearmamento do exército brasileiro não estaria atrelada diretamente à instalação da Companhia Siderúrgica Nacional, mas muito mais à luta imperialista entre as grandes potências.

${ }^{12}$ A chamada "good neighbor policy" foi uma orientação da política externa dos Estados Unidos, sob o governo de Franklin D. Roosevelt, que pregava pela não intervenção deste país nos outros países americanos. Para mais informações ver, Bastos (2015) e Mauad (2014).

${ }^{13}$ Carta de Oswaldo Aranha a Getúlio Vargas. Rio de Janeiro, 3 de setembro de 1937. GV c 1937.08.31/2
} 
Os eventos que precederam a Conferência de Lima podem nos auxiliar no entendimento da formação do território brasileiro alicerçados na política externa do país, de modo que o cenário que se desenhava na Europa, como diria Aranha, era bastante pessimista anos antes do início do conflito mundial. Em carta a Vargas, Aranha apontava, "não tenho dúvidas de que uma nova era de ambições coloniais, determinada por fatores econômicos, mais do que propriamente políticos vai assenhorar-se dos destinos universais" (Aranha, 1936) ${ }^{14}$, o que significava, pelo menos do ponto de vista do então embaixador brasileiro nos Estados Unidos, a necessidade do governo brasileiro se aproximar do seu vizinho do norte.

É nesse sentido que em outro telegrama ao presidente, Aranha

julgava mesmo possível a formação de um bloco continental com estrutura jurídica e ascendência econômica e financeira, tendo sob certos aspectos, um direito americano, uma pauta aduaneira americana, organização de crédito americana etc. (Aranha, 1935) ${ }^{15}$

A discussão viria num contexto em que o governo brasileiro já possuía amplas preocupações com os movimentos bélicos na Europa, como o cenário que já precedia a Guerra Civil Espanhola e a própria invasão da Etiópia pela Itália, já em curso naquele ano de 1935. A inquietação de Aranha com o fato de o Brasil ser o país "com mais problemas extracontinentais e mais terras despovoadas" (Aranha, 1936) ${ }^{16}$, faria com que o embaixador brasileiro se indispusesse com a resistência do Itamaraty em não assumir o pacto de segurança interamericano, que seria proposto na Conferência Interamericana de Consolidação da Paz em dezembro de 1936, em Buenos Aires.

Para Aranha, a perspectiva de haver um acordo entre os Estados do continente americano para a segurança coletiva significaria que "sairíamos de uma proteção intolerável (a política do "big stick ${ }^{17}$ ", antecessora à good neighbor policy) para uma afirmação solidária geral" (Aranha, 1936) ${ }^{18}$, fazendo referência ao fato de que até então a Doutrina Monroe havia pautado todas as discussões sobre a segurança do continente americano. É no ano de 1936, como aponta Danese (2017), que o governo Roosevelt (1933-1945) passa a remodelar a política externa dos Estados Unidos buscando a liderança continental e assim, abrandando a sua política externa nas Américas.

Desse modo, é relevante perceber que a aproximação brasileira dos Estados Unidos não era somente uma tratativa restrita ao campo das relações internacionais, mas também correspondia ao movimento de formação do espaço geográfico brasileiro, a partir do ponto de vista de ordenar o território para atração de capital estrangeiro. Nesse sentido, em carta a Aranha, Vargas, ao falar sobre a aquisição de material para as linhas de transportes do Brasil, dizia, "a simples notícia de um acordo de transportes entre o Lloyd brasileiro e as companhias de navegação ou estradas de ferro americanas é um grande passo para o desenvolvimento econômico" (Vargas, 1936) $)^{19}$. No mesmo sentido, em outra correspondência a Vargas, Aranha observava que

conseguiu-se, aqui, com ação conjunta da Argentina, o que o presidente Roosevelt prometera em discurso: a entrada nos Estados Unidos da América de todo gênero de carnes em conserva, de ambos

\footnotetext{
${ }^{14}$ Carta de Oswaldo Aranha a Getúlio Vargas. Washington, 1 de julho de 1936. GV c 1935.07.01

15 Telegrama de Oswaldo Aranha a Getúlio Vargas. Washington, 20 de julho de 1935. GV c 1935.07.20

${ }^{16}$ Carta de Oswaldo Aranha a Getúlio Vargas. Washington, 19 de setembro de 1936. GV c 1936.09.19.

${ }^{17}$ A diplomacia do Big Stick, corolário da Doutrina Monroe de 1823 preconizava a defesa dos interesses dos Estados Unidos no continente americano, intervindo, inclusive, militarmente onde quer que estes estivessem ameaçados.

${ }^{18}$ Carta de Oswaldo Aranha a Getúlio Vargas. Washington, 19 de setembro de 1936. GV c 1936.09.19

${ }^{19}$ Carta de Getúlio Vargas a Oswaldo Aranha. Rio de Janeiro, 15 de outubro de 1936. Gv c 1936.10.15/1
} 
os países. Isto era impedido pela lei sanitária, e é uma das nossas maiores aspirações econômicas, que visa abrir o mercado, sem limites, para as nossas carnes. Creio que esta foi a nossa maior conquista econômica na conferência internacional. (Aranha, 1936) ${ }^{20}$

Em nota enviada por Aranha à Sumner Wells, subsecretário de Estado dos Estados Unidos daquele período, é explícita a informação de que os Estados Unidos estavam interessados na estabilização da moeda brasileira e que para esse fim colocaria à disposição do Brasil certa quantidade em ouro para lastreamento em moeda (Aranha, 1936) ${ }^{21}$. Meses antes desta nota, Aranha escrevia uma percepção à Vargas sobre os Estados Unidos: "o capital e a iniciativa desta gente estão sofrendo muitíssimo a crise deste país, e eu sinto por toda a parte que eles procuram outras terras. A nossa é a ideal' (Aranha, grifo nosso, 1936) 22.

O cenário interno do Brasil pode contextualizar as disputas que estavam em questão na política externa. $O$ valor das importações de equipamentos industriais estava em recuperação no país, após uma brusca queda nos anos de 1930 e 1931, em consequência da crise da bolsa de valores de 1929, como demonstra a tabela (Gráfico 1). É indispensável constatar que, nesse âmbito, os aspectos políticos e econômicos moldariam as demandas do país na sua política externa, ou seja, o impulso industrial no governo Vargas levaria a alterações territoriais do Estado brasileiro, que imprimiriam nos chamados interesses nacionais pautas que abarcariam a industrialização.

O estado de São Paulo, como demonstra Mamigonian (1976) e Suzigan (1971), já despontava em 1930 como o principal Estado industrialista do país, tendo a figura de Vargas como um dos impulsionadores do empresariado industrial. Os gráficos apontam para o fato de que a retomada da industrialização brasileira após a crise de 1929 foi gradual, o que pode ser visualizado na importação de equipamentos industriais. Esse fator, além de evidenciar o atrelamento da industrialização do país à política externa, aponta para o aspecto de que os ajustes deste se espacializam no território nacional, o que pode, inclusive, explicar o número de empregos gerados no maior polo industrial da federação no período ${ }^{23}$ (Gráfico 2).

\footnotetext{
${ }^{20}$ Carta de Oswaldo de Aranha a Getúlio Vargas. Confidencial. Buenos Aires, 14 de dezembro de 1936. GV c 1936.12.02/2

${ }^{21}$ Notas enviadas a Sumner Wells. 31 de dezembro de 1936. GV c 1936.12.31/2

${ }^{22}$ Carta de Oswaldo Aranha a Getúlio Vargas. Washington, 6 de março de 1936. Gv c 1936.03.06/3

${ }^{23}$ Fausto (2010) e Mamigonian (1976) apontam que já no início do século XX o Estado de São Paulo ultrapassaria o Rio de Janeiro em número de indústrias, tornando-se o estado com maior número de indústrias no país.
} 
Gráfico 1. Valor das importações de equipamentos industriais (valor em libras esterlinas de $2013{ }^{24}$

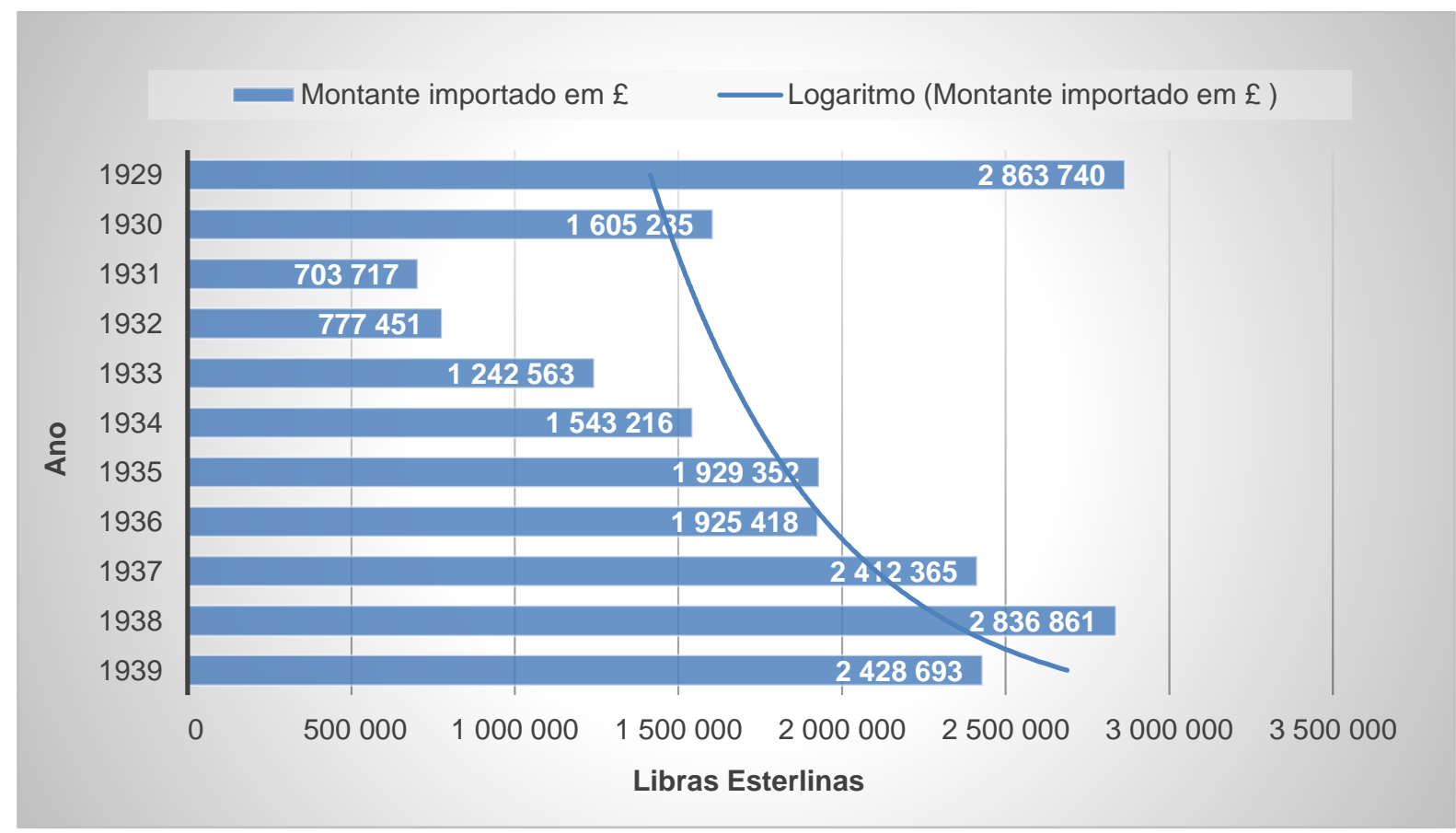

Fonte: IBGE, 2021. Elaborado pelo autor

Gráfico 2. Empregos criados no comércio e na indústria do Estado de São Paulo de 1933 a 1939

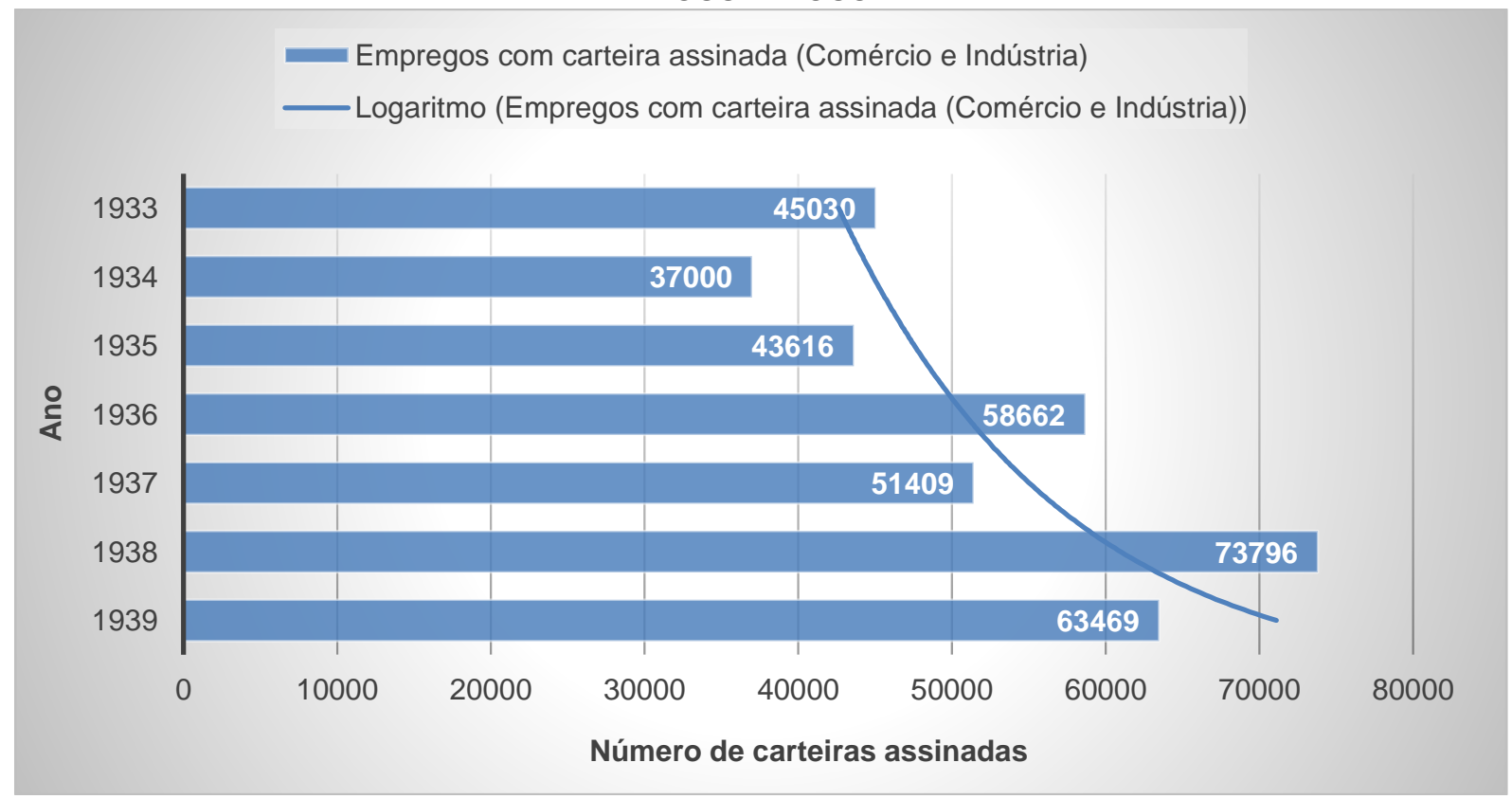

Fonte: IBGE, 2021. Elaborado pelo autor

Ainda que seja inegável a predominância econômica e política dos setores agrários no Brasil, como ressalta Fausto (2010), e as próprias controvérsias sobre o movimento de industrialização brasileira, como já apontava Simonsen e Gudin (2010),

\footnotetext{
${ }^{24} \mathrm{Na}$ cotação de 1913 o valor de câmbio em libras para mil-reis era de 1000 reis $\cong 16 £$. Informação disponível no sítio do IBGE. Disponível em< https://seculoxx.ibge.gov.br/economicas/setor-externo/tabelas>.
} 
não se pode negligenciar a classe industrial brasileira de 1930 como um setor político em ascensão. Nesse sentido, Capelato (2007, p. 119) salienta, "os industriais, os mesmos que haviam feito oposição ao governo Vargas no seu início, foram, pouco a pouco, se aproximando do governo federal".

É interessante notar que a relação entre o território e os influxos da política externa, no caso analisado, evidencia-se no aspecto econômico, político e social da sociedade brasileira. Se como observa Raffestin (1993) o território é o resultado das relações de poder e a política externa parte de uma base territorial para a tomada de ações, então é possível que a política externa tenha um vínculo muito mais próximo com a geografia do que correntemente nos é apresentado. O remodelamento da composição econômica do país levaria à reformulação da estrutura do território nacional. Disso surgiriam novas demandas externas e, embora a aproximação brasileira com os Estados Unidos já datasse de muitos anos antes, o governo brasileiro se movimentaria no exterior para suprir as demandas econômicas e políticas internas, visualizando o papel primordial do comércio norte-americano.

Assim, em fevereiro de 1935 foi assinado um acordo comercial entre o Brasil e os Estados Unidos em que diversos produtos destes dois países teriam uma redução ou isenção de tarifas ${ }^{25}$. Os bastidores deste acordo demonstram como boa parte da classe industrial brasileira protestou contra a tratativa. D'Araujo e Moura (1978) indicam a clara disputa no Congresso brasileiro, industrialistas como Euvaldo Lodi e Roberto Simonsen ${ }^{26}$ se opunham veementemente à ratificação do documento, o que poderia ser um indício da prevalência dos interesses agrários sobre aqueles industriais. O acordo, após ratificação pelo congresso em setembro, e, do senado em novembro seria, então, validado.

Segundo a análise de Curi e Lima (2016), o pensamento de Simonsen estava embebido de ideias protecionistas que contrapunham o livre-comércio. $\mathrm{Na}$ condição de recém-industrialização que se encontrava o Brasil, qualquer acordo de livre-troca com uma potência industrial consolidada seria inaceitável e feriria gravemente não somente os interesses industriais, mas igualmente os interesses nacionais, já que Simonsen identificava na indústria o cerne dos interesses do país. Assim, segundo D'Araujo e Moura (1978, p. 63),

no Brasil, a assinatura do tratado transformou-se numa questão fortemente política, pois a reação dos industriais desencadeou um debate em torno das diretrizes políticas adotadas pelo governo, tanto em termos de política internacional, como no que se refere aos critérios de representatividade do governo para decidir sobre o interesse econômico nacional.

Do nosso ponto de vista, o acordo comercial de 1935, para além da aproximação diplomática entre o Brasil e os Estados Unidos, aponta para o fato de que o território brasileiro é indispensável nas tratativas internacionais por sua condição material intrínseca e inalienável à reprodução do capital.

\footnotetext{
${ }^{25}$ Os produtos norte-americanos consistiam tanto em produtos agrícolas, como manufaturados e maquinário (peixes, leite, cereais, filmes, peças, máquinas agrícolas, entre outros). Do lado brasileiro, mate, bálsamo de copaíba, ipecacuanha, minério de manganês, castanhas e mamona tiveram suas tarifas rebaixadas, e café, cacau, cera de carnaúba, castanhas, óleo de babaçu e madeira tiveram suas tarifas retiradas.

${ }^{26}$ Deputado mineiro entre 1934 a 1956, Euvaldo Lodi foi o primeiro presidente da Confederação Nacional da Indústria (CNI) e presidente da Federação das Indústrias do Rio de Janeiro (FIERJ), ator importante dos interesses industrialistas durante a década de 1930. Roberto Simonsen foi deputado constituinte por São Paulo em 1933, presidente da Federação das Indústrias do Estado de São Paulo e da CNI. Além de político, Simonsen possuí uma vasta obra sobre a industrialização brasileira.
} 
O remodelamento do papel estatal no governo Vargas indica que o território brasileiro estava passando por uma readequação de sua estrutura. Franco (2019, p. 93) verifica que

a via autoritária keynesiana do Estado Novo de Vargas promoverá transformações espaciais, sociopolíticas e econômicas do país, sobretudo depois da derrubada das barreiras alfandegárias (1933) entre os governos estaduais, que fomentou a maior integração mercantil inter-regional e abriu caminho para a divisão regional do trabalho no país.

A composição do território brasileiro começava a transparecer de modo diverso nas tratativas externas do país. O acordo com os Estados Unidos inquietava o nascente setor industrialista, como se pode constatar em D'Araujo e Moura (1978), assim como refletia a proeminência, ainda que enfraquecida, dos setores agrários. Essa relevância pode ser avaliada em números: os produtos agrícolas tiveram um aumento de produtividade e, por consequência, de área cultivada. No caso do Cacau, por exemplo, sua exportação entre 1930 a 1939 cresceu aproximadamente $92 \%$ e sua área de cultivo cresceu 33,98\% no mesmo período. $O$ algodão teve um aumento de $1457 \%$ nos números de sua exportação, resultando no incremento de $280 \%$ da sua área produtora. No caso do algodão, como apontou Suzigan, as indústrias têxteis nacionais utilizavam somente algodão produzido no Brasil, "sendo que $80 \%$ da quantidade utilizada provinham da produção agrícola do próprio estado (São Paulo)" (Suzigan, 1971, p. 104-105). Ainda, outros setores, como o da borracha e do café, apresentariam taxas estáveis de exportação: o café um crescimento de sua exportação em $7,92 \%$ no período, tendo, no entanto, uma queda de $31 \%$ da sua área cultivável $^{27}$. A variação do volume de exportações pode ser visualizada na tabela abaixo (Gráfico 3).

Gráfico 3. Exportação de Produtos Agrícolas no Brasil de 1930 a 1940

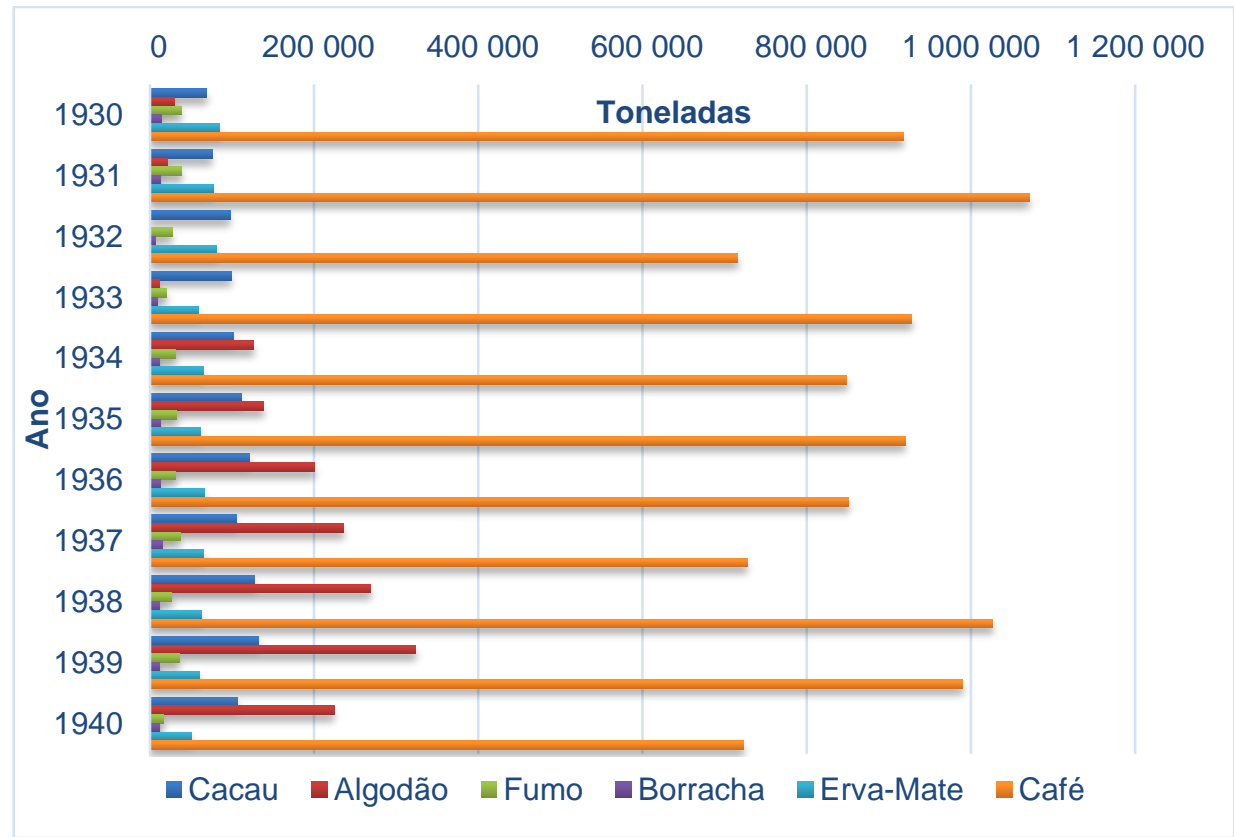

Fonte: IBGE, 2021. Elaborado pelo autor

\footnotetext{
${ }^{27}$ Os dados sobre a área cultivada da borracha não estavam disponíveis para o período. Os dados sobre referentes à área cultivada estão disponíveis em 〈https://seculoxx.ibge.gov.br/economicas/tabelas-setoriais/agropecuaria〉 .
} 
Observando, além disso, que os números da exportação brasileira caem entre o ano de 1939 e 1940, poderemos constatar que esse fato teve como causa o início da Segunda Guerra Mundial, fator extremamente relevante para a política externa brasileira e que geraria impacto em toda a estrutura territorial do país, inclusive com a necessidade de aproximação cautelosa do governo Vargas em relação aos Estados Unidos no início da década de 1940. Ainda que seja possível verificar uma ligeira queda nas exportações de produtos agrícolas brasileiros, é necessário observar que essa condição pode ter sido afetada tanto pela retração das exportações nacionais após a crise de 1929, como pelo desencadeamento da Segunda Guerra Mundial, que implicaria na queda de importação de produtos como o café e o algodão pelos países europeus, este último item em ampla ascensão produtiva.

Levando-se em consideração que o governo brasileiro se mostrava preocupado com a situação europeia já no início da década de 1930, a aproximação varguista em relação aos Estados Unidos parecia se configurar como um ensejo interessante, pois coadunava as necessidades econômicas de grupos políticos que substanciavam o ordenamento territorial do país. A elite agrária e a burguesia urbano-industrial, como indica Fausto (2007a, 2007b, 2010), teriam seus conflitos absorvidos pelo aparato centralizador do Estado Novo, deixando evidente tanto a defesa da industrialização como a proteção aos setores tradicionais agroexportadores.

O acordo comercial de 1935, portanto, convergia também com a organização econômica do país, uma vez que a base do acordo era a eliminação mútua de taxas de importação sobre produtos brasileiros e estadunidenses, e esses produtos eram respectivamente agrícolas e industriais.

Do ponto de vista externo, é necessário apontar que este acordo comercial estava ligado não somente a um fator econômico, mas também geopolítico. O governo brasileiro buscava tecer uma relação com o seu vizinho do norte, procurando evitar o isolamento do país na América do Sul. Nesse sentido, Aranha observava que "os países indo-hispânicos são os nossos inimigos naturais" (Aranha, 1935)28. Essa desconfiança aumentava com a exclusão do Brasil da conferência de paz no Chaco em 1935, de modo que o Itamaraty não demorou a se manifestar consternado com a omissão. Ainda que Aranha tenha insistido na irracionalidade de tal exclusão, é inegável que a desconfiança do Itamaraty em relação aos países vizinhos era um elemento relevante (Aranha, 1935)29.

Assim, diante de um cenário bastante temerário, tanto do ponto de vista regional como mundial, a política externa brasileira deveria funcionar como um amortecedor das expectativas internas. Desse modo, imprimiriam no campo exterior elementos que constituíssem um espectro de estabilidade e poder militar que, por sua vez, atenuassem a força centrípeta dos Estados Unidos, que buscavam em toda a América o estabelecimento de relações assimétricas de poder. Nesse sentido, Aranha, aponta que,

se a redução do intercâmbio e das trocas continuar orientando os povos mais fortes, privados do comércio em geral, para o comércio exclusivo com suas possessões, a resultante será o isolamento dos Estados Unidos e, em consequência, a necessidade para este de criar colônias para comerciar como estão fazendo os demais. (Aranha, 1935) 30

Desse modo, segundo Aranha, os objetivos brasileiros diante desse cenário seriam

\footnotetext{
${ }^{28}$ Carta de Oswaldo Aranha a Getúlio Vargas. Washington, 6 de março de 1935. GV c 1935.03.06/1

${ }^{29}$ Carta de Oswaldo Aranha a Getúlio Vargas. Washington, 17 de abril de 1935. GV c 1935.04.17

${ }^{30}$ Carta de Oswaldo Aranha a Getúlio Vargas. Washington, 1 de julho de 1935. GV c 1935.07.01
} 
a) cuidar dos países que agora e durante longo prazo, necessitarão dos seus produtos; b) cuidar de produzir tudo quanto se importa de países que estão desenvolvendo a "política colonial" afim de libertarem-se das importações de nosso país. (Aranha, 1935) ${ }^{31}$

Testemunhando os objetivos da política externa brasileira, Aranha apresentaria algumas linhas de ação externa do governo Vargas. Assim, ultrapassando a concepção de que a proximidade entre o governo brasileiro e os Estados Unidos está inscrita no aspecto posicional do Brasil, é possível visualizar o remodelamento do território do país a partir da construção de novos interesses nacionais. Ainda que características inatas ao território brasileiro, como dimensão territorial, disponibilidade de recursos naturais e grandeza da população, fossem relevantes para 0 estabelecimento de acordos internacionais, 0 remodelamento territorial seria fundamental para lançamento das diretrizes externas. Em outras palavras, o conteúdo documental diplomático demonstra uma relação complexa entre a formação territorial brasileira e o pensamento da política externa do país, ao menos durante o período analisado, o que, por conseguinte, nos sugere que o debate geográfico tem muito a explorar nesse campo.

\section{CONCLUSÃO}

A discussão apresentada ao longo desse artigo vislumbrava encetar um debate muito necessário à geografia. A política externa, como uma política de Estado, carece de discussão territorial e, por consequência, geográfica. O levantamento das concepções internacionalistas sobre entendimentos dos conceitos muito debatidos no interior da geografia nos demonstra a carência e a profundidade da lacuna deixada, em consequência do afastamento de duas áreas componentes das políticas de Estado.

É notável como conceitos construídos pelo debate geográfico não extrapolaram as construções acadêmicas e não adentram, por exemplo, o Ministério das Relações Exteriores, de modo que as concepções sobre o território, como foi debatido aqui, são mantidas num terreno muito restrito no qual as qualificações territoriais findam na valoração de população, área, recursos, entre tantos outros itens. O território, ainda que o debate geográfico muito insista, não é visualizado como um todo em movimento pela política externa, que insiste em valorar o aspecto posicional do território nacional, aproximando-se de uma concepção clássica da geopolítica.

Dois aspectos importantes florescem com a análise da política externa dos anos de 1930 durante o governo Vargas. Primeiro, demonstra o deslocamento dos interesses setoriais para a esfera da política externa, construindo novas condições de ordenamento territorial, seja na construção do espaço urbano-industrial, seja na manutenção do espaço agrário exportador. Segundo, em que pese à concepção estática e posicional do território prevalente na política externa, este é constituinte e constituído pelas ações no campo das políticas internacionais de um país, demonstrando ser conteúdo incontroverso das tratativas externas do Estado.

O acordo comercial de 1935 demonstra a prevalência dos interesses agrários sob a indústria nacional que, ainda que em ascensão, não ultrapassava as barreiras internacionais da divisão internacional do trabalho. A posição do Brasil frente aos Estados Unidos é resultado da condição territorial brasileira, voltada em todos os seus

\footnotetext{
${ }^{31}$ Ibid.
} 
aspectos, culturais, econômicos, sociais e políticos para a condição exportadora de produtos agrários do país. O acordo, possuía essa dupla função, era resultado da condição territorial brasileira e quanto assinado, passou a ratifica-la.

\section{AGRADECIMENTO}

Agradeço ao Conselho Nacional de Desenvolvimento Científico (CNPq) o qual financiou esta pesquisa.

\section{REFERÊNCIAS BIBLIOGRÁFICAS}

AGNEW, J. Mastering Space: hegemony, territory and international political economy. Londres/Nova lorque: Routledge, 2003.

-Globalization and Sovereignty: beyond the territorial trap. Los Angeles: Rowman and Littlefield, 2018.

ANDRADE, M. C. de. A questão do território no Brasil. 2.ed. São Paulo: Hucitec, 2004.

ARON, R. Paz e guerra entre as nações. Brasília: Universidade de Brasília, 2002.

BRASIL. Decreto no 542, de 24 de dezembro de 1935. Disponível em < https://www2.camara.leg.br/legin/fed/decret/1930-1939/decreto-542-24-dezembro1935-555656-publicacaooriginal-74987-pe.html>. Acesso em 15 de jun. de 2021.

BASTOS, P. P. Z. Da Diplomacia do Dólar à Diplomacia da Boa Vizinhança: continuidades e diferenças na política dos Estados Unidos para a América Latina (1898-1933). Nova Economia [online]. 2015, v. 25, n. 1 Disponível em: < https://www.scielo.br///neco/a/DzwYzpj4C36Z467y8RTvrYk/?lang=pt>. Acesso em 26 de mai. de 2021.

BECKER, B. A Geografia e o Resgate da Geopolítica. Espaço Aberto, v. 2, n. 1, p. 117- 150, Jul. 2012a. Disponível em: $<$ https://revistas.ufri.br/index.php/EspacoAberto/article/view/2079/1846>. Acesso em: 26 Set. 2020.

K. Manual do candidato: geografia. Brasília: FUNAG, 2012b.

CURI, L. F. B.; LIMA, D. B. M. Roberto Simonsen and the Brazil-U.S. Trade Agreement of 1935: economic ideas and political action. Nova Economia. v. 25, n. 3, 2016. Disponível em: $<$ https://revistas.face.ufmg.br/index.php/novaeconomia/article/view/3255>. Acesso em: 7 jul. 2020.

CAPELATO, M. H. R. O Estado Novo: O que trouxe de novo. In: FERREIRA, J, DELAGADO, L. de A. N. O Brasil Republicano: o tempo do nacional-estatismo-do início da década de 1930 ao apogeu do Estado Novo. Rio de Janeiro: Civilização Brasileira, 2007. 
CASTRO, I. E; CORREA, R. L.; GOMES, P. C. G. Geografia e Política: Território, escalas de ação e instituições. Rio de Janeiro: Editora Bertrand Brasil, 2005.

CATAIA, M. A. Território político: fundamento e fundação do estado. Sociedade e natureza. Uberlândia, v. 23, n. 1, p. 115-125, 2011. Disponível em $<$ http://www.scielo.br/scielo.php?script=sci arttext\&pid=S198245132011000100010\&

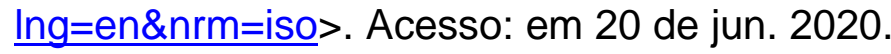

CLAUSEWITZ, C. V. Historical and Political Writings. New Jersey: Princeton University Press, 1992.

D'ARAÚJO, M. C.; MOURA, G. O tratado comercial Brasil-EUA de 1935 e os interesses industriais brasileiros. Revista de Ciência Política, Rio de Janeiro, v. 21, n. 1 , p. 55-73, 1978.

DANESE, S. Diplomacia Presidencial: História e crítica. Brasília: Funag, 2017.

FAUSTO, B (Org). História Geral da Civilização Brasileira: Sociedade e Política (1930-1964). São Paulo: Bertrand, 2007a.

. História Geral da Civilização Brasileira: economia e cultura (1930-1964). São Paulo: Bertrand, 2007b.

FAUSTO, B. A Revolução de 1930: Historiografia e História. São Paulo: Companhia das Letras, 2010.

GOTTMANN, J. The significance of territory. Charlottesville: Universidade de Virginia, 1973.

GUDIN, E.; SIMONSEN, R. A controvérsia do planejamento na economia brasileira. Brasília: IPEA, 2010.

HARVEY, David. O enigma do capital: e as crises do capitalismo. São Paulo: Boitempo, 2011.

MAMIGONIAN, A. O processo de industrialização em São Paulo. Boletim Paulista de Geografia. São Paulo: AGB, n. 50, p. 83-101, 1976.

MARTIN, A. R. Brasil, geopolítica e poder mundial: o anti-Golbery. São Paulo: Hucitec, 2018.

MAUAD, A. M. Fotografia e a cultura política nos tempos da política da Boa Vizinhança. Anais do Museu Paulista: História e Cultura Material [online]. 2014, v. 22, n. 1, pp. 133-159. Disponível em: < https://www.scielo.br///anaismp/a/5zKtCvr4rFZN7qKzfmSh8nM/?lang=pt>. Acesso em 09 de jun. de 2021.

MORAES, A. C. R. Território e História no Brasil. São Paulo: Annablume, 2005 
MORGENTHAU, H. J.A política entre as nações: a luta pelo poder e pela paz. Brasília: Universidade de Brasília, 2003.

MOURA, G. Autonomia na dependência: a política externa brasileira de 1935 a 1942. Rio de Janeiro: Nova Fronteira, 1980.

. Relações Exteriores do Brasil 1939-1950. Brasília: Funag, 2012.

RAFFESTIN, C. Por uma geografia do poder. São Paulo: Ática, 1993.

RAFFESTIN, C. A produção das estruturas territoriais e sua representação. In: SAQUET, M. A; SPOSITO, E. S (org.). Territórios e Territorialidades: teorias, processos e conflitos. São Paulo: Expressão Popular, 2009.

RATZEL, F. Der staat und sein boden geographisch betrachtet. Leipzig: S. Hirzel, 1896.

ROSEIRA, A. M. Geografia e Relações Internacionais. Revista Continentes, n. 7, p. 64-88, jul. 2015.2 Disponível em: $<$ http://www.revistacontinentes.com.br/continentes/index.php/continentes/article/view /81>. Acesso em: 18 ago. 2020.

SANTOS, M. Técnica, espaço e tempo. São Paulo: Hucitec, 1994.

Por uma geografia nova: da crítica da geografia a uma geografia crítica. São Paulo: EdUSP, 2002.

- Economia Espacial: críticas e alternativas. São Paulo: Editora da Universidade de São Paulo, 2003.

A natureza do espaço: técnica e tempo, razão e emoção. São Paulo: Editora da Universidade de São Paulo, 2006.

SAQUET, M. A. Abordagens e concepções de território. São Paulo: Expressão Popular, 2007.

SAQUET, M. A.; SILVA, S. S. Milton Santos: concepções de geografia, espaço e território. Geo UERJ. Rio de Janeiro, v. 2, n. 18, p. 24-42, 2011. Disponível em: $<$ https://www.e-publicacoes.uerj.br/index.php/geouerj/article/view/1389/1179>.

Acesso em: 29 jun. 2020.

SILVA, C.A. F. A modernização distópica do território. Rio de Janeiro: Consequência, 2019.

SILVA, G. C. Conjuntura Política Nacional: O Poder Executivo e Geopolítico do Brasil. Rio de Janeiro: Livraria José Olympio, 1981.

SOUZA, M. J. L. "Território" da divergência (e da confusão): em torno das imprecisas fronteiras de um conceito fundamental. In: SPOSITO, E.; SAQUET, M. 
A. Territórios e territorialidades: teorias, processos e conflitos. Expressão Popular: São Paulo, 2009.

SUZIGAN, W. A Industrialização de São Paulo: 1930-1945. Revista Brasileira de Economia, Rio de Janeiro, v. 25, n. 2, p. 89-112, 1971. Disponível em: $<$ http://bibliotecadigital.fgv.br/ojs/index.php/rbe/article/view/51>. Acesso em: 09 jul. 2020.

WIGHT, M. A política do poder. Brasília: Editora Universidade de Brasília, 2002.

\section{Acervos CPDOC}

Carta de Oswaldo Aranha a Getúlio Vargas. Washington, 6 de março de 1935. GV c 1935.03.06/1.

Carta de Oswaldo Aranha a Getúlio Vargas. Washington, 17 de abril de 1935. GV c 1935.04.17.

Carta de Oswaldo Aranha a Getúlio Vargas. Washington, 1 de julho de 1935. GV c 1935.07.01.

Notas enviadas a Sumner Wells. 31 de dezembro de 1936. GV c 1936.12.31/2.

Carta de Oswaldo Aranha a Getúlio Vargas. Washington, 6 de março de 1936. Gv c 1936.03.06/3.

Telegrama de Oswaldo Aranha a Getúlio Vargas. Washington, 20 de julho de 1935. GV c 1935.07.20.

Carta de Oswaldo Aranha a Getúlio Vargas. Washington, 19 de setembro de 1936. GV c 1936.09.19.

Carta de Getúlio Vargas a Oswaldo Aranha. Rio de Janeiro, 15 de outubro de 1936. Gv c 1936.10.15/1.

Carta de Oswaldo de Aranha a Getúlio Vargas. Confidencial. Buenos Aires, 14 de dezembro de 1936. GV c 1936.12.02/2.

Carta de Oswaldo Aranha a Getúlio Vargas. Rio de Janeiro, 3 de setembro de 1937. GV c 1937. 08. 31/2.

Carta de Oswaldo Aranha a Getúlio Vargas. Washington, 1 julho de 1936. GV c 1935. 07.01 .

Carta de Oswaldo Aranha a Getúlio Vargas, s/d, documento n¹1. GV c 1939.01.09.

Projeto de discurso a ser pronunciado pelo senhor presidente da república, por ocasião da assinatura do Tratado de Cooperação Amazônica em 3 de julho de 1978. AAS mre ai 1977.03.02.

Rubens Antônio Brabosa, embaixador do Brasil em Washington, publicado em Wagner Menezes (org.) direito internacional no cenário contemporâneo (Curitiba: Jurua, 2003), p.193-198. Alca e Mercosul: implicações estratégicas para o Brasil, 11 de julho de 1999.RBA mpc w 1999.03.10. 